\title{
Characterization of Snowfall Rates, Totals, and Snow-to-Liquid Ratios in Electrified Snowfall Events Identified by the Geostationary Lightning Mapper
}

\author{
SEBASTIAN S. HARKEMA \\ Department of Atmospheric and Earth Science, University of Alabama in Huntsville, Huntsville, Alabama \\ EMILY B. BERNDT AND CHRISTOPHER J. SCHULTZ \\ NASA Marshall Space Flight Center, Huntsville, Alabama
}

(Manuscript received 19 June 2019, in final form 29 January 2020)

\begin{abstract}
It has been theorized that thundersnow (TSSN) occurs in conjunction with heavy snowfall rates and in geographical regions where heavy-banded snow occurs more frequently. This study aims to objectively and quantitatively identify characteristics associated with TSSN to improve the situational awareness of heavy snowfall and associated hazards. The Geostationary Lightning Mapper (GLM), National Environmental Satellite Data and Information Services (NESDIS) merged Snowfall Rate (mSFR) product, and surface observations were utilized to characterize snowfall accumulation, snow-to-liquid ratio (SLR) values, and radar characteristics of heavy snowfall events from a GLM perspective. When at least 2 in. of snowfall accumulation occurred, areas with TSSN flashes identified by the thundersnow detection algorithm (TDA) were likely to receive, on average, a total of $24.5 \mathrm{~cm}$ (9.6 in.) of snowfall. TSSN was more likely to occur in snowfall rates less than $2.54 \mathrm{~cm} \mathrm{~h}^{-1}\left(1 \mathrm{in} . \mathrm{h}^{-1}\right)$ and be associated with snow-to-liquid ratio (SLR) values between 8:1 and 10:1. It was determined that TSSN flashes observed by GLM occurred in isothermal reflectivity values less than $30 \mathrm{dBZ}$ and average spatial offsets of $131 \mathrm{~km}$ between the lightning flash location and the heaviest snowfall rates were observed. GLM flashes in proximity of National Lightning Detection Network cloud-toground flashes and tall structures were found to be statistically different $(p<0.05)$ regarding snowfall rates, SLR values, and various Multi-Radar Multi-Sensor variables compared to other TSSN flashes. It was inferred that tower TSSN flashes, on median, were more likely to initiate within light-to-moderately rimed snowfall. Last, a heavy snowfall event was analyzed to demonstrate the capability of these products in identifying storm characteristics associated with TSSN.
\end{abstract}

\section{Introduction}

It is commonly accepted that thundersnow (TSSN) is the coexistence of lightning and/or thunder and snowfall observations (Curran and Pearson 1971; Schultz 1999; Market et al. 2002; Crowe et al. 2006; Market and Becker 2009). Schultz (1999) mentioned that the lack of scientific inquiry regarding TSSN, compared to lightning in convective storms, was low because of the perceived lack of threat and perceived rarity associated with the phenomena. As such, TSSN draws a fascination with the public and scientists alike and still poses safety hazards for the public and has been shown to cause damage to life and property (Herschel 1888; Holle et al. 1997; Cherington et al. 1998). Kumjian and Deierling (2015)

\footnotetext{
Corresponding author: Sebastian S. Harkema, sebastian.harkema@ nasa.gov
}

mention lightning-related incidents at ski resorts and the increased threat of aviation hazards (i.e., aircraft initiated lightning) in electrified winter clouds.

Many studies have theorized and examined lightning initiation and the charging mechanisms within clouds (e.g., Paluch and Sartor 1973; Takahashi 1978; Jayaratne et al. 1983). A leading theory for lightning initiation is associated with noninductive charging, which requires the coexistence of supercooled water, graupel, and ice crystals (Takahashi 1978; Saunders et al. 2006). All three particle types exist within winter storms at temperatures that facilitate charge separation and thus make TSSN possible (e.g., Trapp et al. 2001; Rust and Trapp 2002; Rauber et al. 2014; Schrom and Kumjian 2016; Takahashi et al. 2017). Additionally, studies have noted the increased likelihood of lightning associated with tall human-built structures in winter storms and is likely a result of the charging structures of winter 
storms being closer to the ground (e.g., Miyake et al. 1990; Kingfield et al. 2017; Schultz et al. 2018).

Market et al. (2002) identified 191 TSSN events from 1961 to 1990 and mentioned that TSSN events were limited in areal extent, short lived, and typically have light-to-moderate snowfall rates. Rauber et al. (2014) found that TSSN tend to occur on the southern side of the snowband and comma head within midlatitude extratropical cyclones and suggest that mesoscale features were embedded within the larger synoptic snowband. TSSN occurring in this location was likely caused by the coexistence/collision of supercooled water and heavily rimed particles that enhance the electric field (Reynolds et al. 1957; Takahashi 1978). In contrast, Market and Becker (2009) found that TSSN was more likely to occur on the leading edge of the advancing snowbands for organized convection. Using radar reflectivity as a proxy for snowfall rates, they found that TSSN flashes and maximum snowfall rates were only weakly correlated and more TSSN flashes occurred downstream of the highest radar reflectivity (i.e., inferred highest snowfall rates). Additionally, they suggested TSSN flashes could be used to nowcast an impending increase in snowfall rates based on an increase in radar reflectivity following TSSN.

Reflectivity alone does not provide quantifiable snowfall rates, however, and snowfall rates can vary greatly from one region of the system to another. During the 10 January 2011 TSSN event in Huntsville, Alabama, Schultz et al. (2018) observed snowfall rates on the order of $5-8 \mathrm{~cm} \mathrm{~h}^{-1}$ in areas that would eventually receive $20-30 \mathrm{~cm}$ of total snowfall accumulation. Furthermore, Crowe et al. (2006) demonstrated that TSSN tended to be associated with storms that produce higher $(>15 \mathrm{~cm})$ storm-total snowfall accumulation but TSSN did not necessarily occur in regions with the highest accumulating snowfall. This suggests that TSSN can be used as an indicator for potential higher storm total snowfall accumulations if the phenomena occurs. However, Crowe et al. (2006) does not discuss which regions of the storm to expect higher snowfall nor the snowfall accumulation where TSSN occurred.

To better identify and characterize TSSN, Harkema et al. (2019) formulated a thundersnow detection algorithm (TDA) that objectively identified TSSN using Geostationary Operational Environmental SatelliteEast (GOES-East; Schmit et al. 2005) Level-2 Geostationary Lightning Mapper (GLM; Goodman et al. 2013) data, National Environmental Satellite Data and Information Service (NESDIS) merged Snowfall Rate (mSFR; Meng et al. 2017a,b) product, and nearest-neighbor statistics (Bentley 1975). Through the algorithm, Harkema et al. (2019) observed that $22.8 \%$ of TSSN flashes detected by
GLM do not correspond with any National Lightning Detection Network (NLDN; Cummins and Murphy 2009) data and suggests that TSSN is currently underreported (Kumjian and Deierling 2015). Furthermore, this study builds upon Harkema et al. (2019) by altering the TDA to investigate the potential relationship between TSSN and heavy-banded snowfall characteristics (e.g., snowfall rates).

Forecasting and nowcasting of heavy snowfall can be difficult owing to the spatial and temporal heterogeneity of mesoscale processes (Uccellini et al. 1995; Wiesmueller and Zubrick 1998; Nicosia and Grumm 1999; Moore and Graves 2005; Novak et al. 2006; Baxter and Schumacher 2017), microphysical characteristics (Schrom and Kumjian 2019), and variance in scattering processes of different ice habits within heavybanded snowfall (Molthan and Petersen 2011). One aspect that can drastically impact snowfall forecasts is the inferred snow-to-liquid ratio (SLR) values of the snowfall (Roebber et al. 2003). Colle et al. (2014) demonstrated that large aggregates (e.g., comprising dendrites) have high SLR values, while compact ice particle habits and heavily rimed particles (i.e., needles, bullets, graupel) were associated with lower SLR values. The SLR values within heavy snowfall varied drastically within the comma head of a cyclone. Near the cyclone center, heavily rimed particles were found, while plates and bullets commonly occurred in the outer comma head (Colle et al. 2014). The region of heavily rimed particles, near the center of the comma head, coincided with the environment that was preferential for TSSN (Rauber et al. 2014). This suggests that TSSN can potentially by used as a proxy for SLR values in a nowcasting timeframe.

To understand the physical processes that impact SLR values, Roebber et al. (2003) employed a neural network and found that four main factors could be utilized to forecast the potential for SLR values: surface winds, temperature, relative humidity, and time of year. Additionally, Baxter et al. (2005) created a SLR value climatology and found that mean SLR values were closer to 13.53 to 1 compared to the 10 -to1 rule of thumb. Unfortunately, this climatology only examined long-term characteristics of SLR and may not be representative for the processes on shorter time scales including those associated with heavy snowfall. Currently, SLR values are determined by daily observations, from trained weather observers, from Cooperative Summary of the Day (COOP; NWS 2019) stations and/or the Community Collaborative Rain, Hail, and Snow (CoCoRaHS; Cifelli et al. 2005) network. These data were a summary of what occurred in the previous $24 \mathrm{~h}$ or a summation of four 6-h observations. Examining COOP and CoCoRaHS 
derived SLR every $24 \mathrm{~h}$ would be more representative than any individual climatology but still results in a relatively coarse spatial and temporal analysis.

Characterization of the environment in regard to the predictability of snowfall rates and the potential for snowfall accumulation could identify environments conducive for TSSN prior to initiation. Concurrently, this understanding could be utilized to quantify snowfall rates, liquid ratios, and totals in data sparse areas that are affected by heavy snowfall (e.g., Dolif Neto et al. 2009; Adhikari and Liu 2019) through the use of the characteristics of lightning from the GLM (i.e., flash size and total optical energy). With the spatial and temporal availability of GLM and the development of the TDA, further objective characterization of the storm characteristics (SLR, snowfall rates, and accumulation) and underlying characteristics inferred from radar [reflectivity, vertically integrated ice (VII); Carey and Rutledge (2000), vertically integrated liquid (VIL)] of the parent environment in which the lightning develops is possible. Thus, the objectives of this study are:

1) Develop a high-spatial resolution SLR dataset and compare to Baxter et al. (2005).

2) Modify the TDA of Harkema et al. (2019) to characterize TSSN flashes observed by GLM based on derived high-resolution SLR values, snowfall rates, and snowfall accumulation.

3) Analyze the 13-17 April 2018 blizzard to investigate the microphysical characteristics and predictability of TSSN by examining isothermal (i.e., $-10^{\circ},-15^{\circ},-20^{\circ} \mathrm{C}$ ) reflectivity, VII, and VIL to compare with previous work by Mosier et al. (2011), Seroka et al. (2012), and Adhikari and Liu (2019).

\section{Dataset}

\section{a. Snow-to-liquid ratio}

SLR values are directly correlated with observed total snowfall accumulations and have strict guidelines to properly measure snowfall compared to rainfall. Presently, there are over 10000 trained volunteers that take daily observations as part of the National Weather Service (NWS) COOP program. COOP observers measure and report snowfall in tenths of an inch on a 24-h basis and collect snow cores to be melted down to determine the liquid equivalent (NWS 2017). These measurements are valuable for forecasters as they provide information in potentially data sparse regions and verification for numerical weather prediction models. SLR values are calculated by taking the ratio of measured snowfall accumulation and liquid equivalent. Currently, the National Oceanic and Atmospheric Administration (NOAA) National Centers for Environmental Information (NCEI) provides an archive of COOP data.

\section{b. Snowfall accumulation}

To further validate and visualize snowfall accumulations the National Operation Hydrological Remote Sensing Center (NOHRSC) provides a national snowfall analysis. This analysis is generated by interpolating 24-h observations of snowfall accumulations from COOP, CoCoRaHS observations, and NWS spotter reports (NWS 2015). This analysis provides high-resolution snowfall accumulations on 6-, 24-, 48-, and 72-h durations as well as seasonal totals.

\section{c. Merged Snowfall Rate product}

The mSFR product, from NESDIS, blends MultiRadar Multi-Sensor (MRMS; Zhang et al. 2016) and Global Precipitation Measurement (GPM; Hou et al. 2014; Skofronick-Jackson et al. 2017) passive microwave sensor data to estimate snowfall rates within the continental United States (CONUS) every $10 \mathrm{~min}$ with a spatial resolution of $1 \mathrm{~km} \times 1 \mathrm{~km}$. The $\mathrm{mSFR}$ product currently utilizes the following passive microwave sensors: GPM Microwave Imager (GMI), Special Sensor Microwave Imager/Sounder (SSM/IS), Advanced Technology Microwave Sounder (ATMS), Microwave Humidity Sounder (MHS), and Advanced Microwave Sounder Unit (AMSU). Snowfall rates derived from these sensors have been shown to approximate snowfall rates prior to snowfall reaching the surface (Meng et al. 2017b; Ferraro et al. 2018). This is particularly beneficial in data sparse regions that deal with radar beam blockage (e.g., Intermountain West). Given the lack of temporal coverage of the passive microwave sensors, MRMS is merged with the passive microwave observations to fill in the gap between satellite overpasses. The ability to incorporate MRMS into this product allows for the ability to track local maxima within the snowfall as well as increasing the spatial resolution in order to depict mesoscale features. Snowfall rates derived from MRMS are essentially liquid precipitation rates associated with the "snow" precipitation flag (Huan Meng, NESDIS, personal communication). Since this product was developed for operational forecasters, users have a choice of applying different SLR values (i.e., 1:1, 10:1, 18:1, and 35:1) when analyzing this product within the Advanced Weather Interactive Processing System (AWIPS). Assuming a 10:1 SLR, the mSFR product is valid for snowfall rates from $0.20 \mathrm{~cm} \mathrm{~h}^{-1}$ $\left(0.08 \mathrm{in.} \mathrm{h}^{-1}\right)$ to $5.08 \mathrm{~cm} \mathrm{~h}^{-1}\left(2.00 \mathrm{in} . \mathrm{h}^{-1}\right)$ (Meng et al. 2017b). The MRMS portion of the mSFR product was 
used in all analyses within this study as it provides superior temporal and spatial coverage compared to the passive microwave sensor data. For our situation, a 1:1 SLR is important because it can be used to estimate of accumulated liquid equivalent for the duration of the cases. Dividing the observed snowfall accumulation by the estimated liquid equivalent provides a more realistic SLR distribution of each of the cases compared to assuming a uniform SLR value such as 10:1 or $13: 1$.

\section{d. Multi-Radar Multi-Sensor}

MRMS provides a seamless national 3D radar mosaic with high spatial $(1 \mathrm{~km} \times 1 \mathrm{~km})$ and temporal $(2 \mathrm{~min})$ resolutions (Zhang et al. 2016). MRMS provides seven surface precipitation classifications including snow. Within MRMS, precipitation is labeled as snow when the surface temperature is below $2^{\circ} \mathrm{C}$ and the wet-bulb temperature is below $0^{\circ} \mathrm{C}$ (Zhang et al. 2016). It should be noted that the MRMS rain/snow transition region is abrupt as there is no mixed precipitation flag and most likely classifies this region as cold stratiform rain (S. Martinaitis, CIMMS/NSSL, 2019, personal communication).

Furthermore, MRMS also produces radar-derived products including VII, VIL, and isothermal reflectivity and allows for analysis of these variables on a larger scale compared to a single Doppler radar (Smith et al. 2016). For example, the derived VII from MRMS can be used to evaluate changes in updraft intensity, which has been shown to have a positive relationship with total lightning activity (Deierling et al. 2005; Schultz et al. 2017).

\section{ISOTHERMAL REFLECTIVITY, VERTICALLY INTEGRATED ICE, AND VERTICALLY INTEGRATED LIQUID}

Mosier et al. (2011) and Seroka et al. (2012) examined isothermal reflectivity in summer convection (i.e., $-10^{\circ}$, $-15^{\circ},-20^{\circ} \mathrm{C}$ ) and VII to demonstrate the predictability of lightning. Specifically, Mosier et al. (2011) found that $25-\mathrm{dB} Z$ reflectivity at $-20^{\circ}$ and $-15^{\circ} \mathrm{C}$ were the best predictors of cloud-to-ground $(\mathrm{CG})$ and intracloud (IC) lightning, respectively. In contrast, Gremillion and Orville (1999) and Vincent et al. (2003) demonstrated that the $40-\mathrm{dB} Z$ echoes at the $-10^{\circ} \mathrm{C}$ isotherm level was the best predictor for the beginning of $\mathrm{CG}$ activity. VII is defined as

$$
\mathrm{VII}=1000 \pi \rho_{i} N_{0}^{3 / 7}\left(\frac{5.28 \times 10^{-18}}{720}\right) \int_{H_{-10}}^{4 / 7} Z^{H_{-40}} d H,
$$

where $\rho_{i}$ is the density of ice $\left(917 \mathrm{~kg} \mathrm{~m}^{-3}\right), N_{0}$ is the intercept parameter $\left(4 \times 10^{6} \mathrm{~m}^{-4}\right), Z$ is the reflectivity value $\left(\mathrm{mm}^{6} \mathrm{~m}^{-3}\right)$, and $H_{-10}$ and $H_{-40}$ are the height of the $-10^{\circ}$ and $-40^{\circ} \mathrm{C}$ isotherm levels $(\mathrm{m})$, respectively. Additionally, $N_{0}$ is for an assumed exponential snow size distribution assumed in single-moment microphysics. Essentially, VII is the integrated reflectivity within the mixed-phase region and is used to infer the amount of ice within that layer despite the fact that liquid particles may significantly contribute to $Z$ in this layer, and, thus to VII.

\section{e. Geostationary Lightning Mapper}

On 18 December 2017, the GLM on board the GOESEast satellite, became operational and provides a hemispherical view of lightning from $54^{\circ} \mathrm{N} / \mathrm{S}$ with a temporal and spatial resolution of $2 \mathrm{~ms}$ and $8 \mathrm{~km}$, respectively (Goodman et al. 2013; Rudlosky et al. 2019). GLM is an optical sensor that utilizes a narrow 1-nm band centered on the 777.4-nm wavelength that allows for the observation of lightning during the day and night (Christian and Goodman 1987; Rudlosky et al. 2019). Beyond the detection of lightning in severe weather, GLM has been documented identifying TSSN in a variety of environments (Schultz et al. 2018; Harkema et al. 2019). GLM data consist of three main components: events, groups, and flashes (Goodman et al. 2013). An event is when a single GLM pixel $\left(\sim 64 \mathrm{~km}^{2}\right)$ is illuminated more than a background threshold. GLM events that are adjacent to each other and occur in a single frame are classified as a GLM group. GLM flashes are currently defined as a conglomerate of GLM groups that occur within a Euclidean distance bounded by $330 \mathrm{~ms} / 16.5 \mathrm{~km}$ (Goodman et al. 2013). For a complete description of GLM capabilities and specifications, see Goodman et al. (2013).

\section{Methodology}

\section{a. The thundersnow detection algorithm}

The TDA identifies the coincident occurrence and location of lightning and snow by comparing GLM to the MRMS portion of the mSFR product (Fig. 1). For a full description and methodology of the TDA see Harkema et al. (2019). Summarized here, the process for a classifying a GLM flash as TSSN, along with a confidence, can be broken down into five steps:

1) First, GLM groups are binned to match the same 10-min temporal resolution of the mSFR product. GLM groups were chosen because they provide spatial context to the flash's size given that GLM flash data reports the mean location of all GLM groups.

2) Next, nearest-neighbor statistics are used to determine where overlap between GLM flash and group 


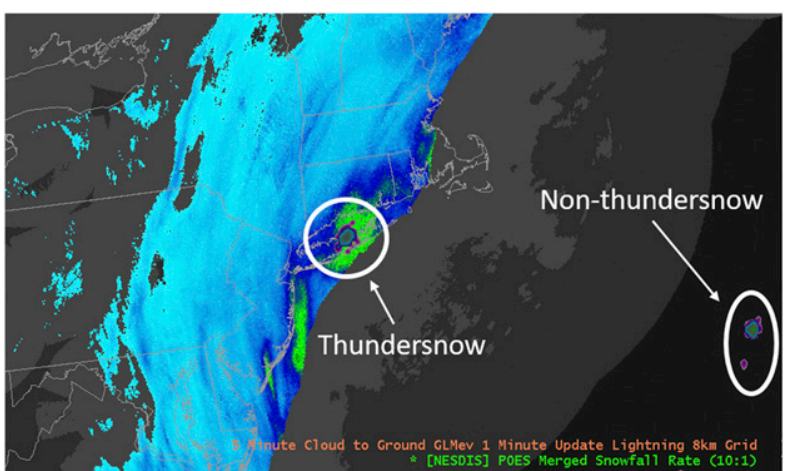

FIG. 1. AWIPS display of the NESDIS mSFR product (blues and greens) and GLM data (blobs in white circles) at 1410 UTC 4 Jan 2018. This demonstrates the premise of using the overlap of these two datasets to objectively identify thundersnow using the thundersnow detection algorithm.

data and places where the mSFR product has identified snowfall.

3) The number of mSFR pixels within a $0.15^{\circ}$ distance around each GLM group location are then counted to characterize if the GLM group occurred entirely in snowfall (as identified by the mSFR algorithm) or if there are locations close to the group that may be mixed precipitation or all rain. The maximum number of mSFR pixels for any $0.15^{\circ}$ search radius is $866\left(\pi \times 16.6^{2}\right)$.

4) GLM groups are matched up with the GLM flash data using common GLM Flash ID information contained in the Level-2 data. The mSFR pixel count is then computed by averaging the number of snowfall pixels identified at each GLM group location for the entire GLM flash.

5) All GLM flashes with an average mSFR count of $\geq 700$ are then classified as observed lightning within snowfall (i.e., TSSN) and snowfall rate information is extracted.

\section{b. High-resolution snow-to-liquid ratio values}

For each of the 21 snowfall cases in Harkema et al. (2019) liquid equivalent was derived by aggregating the mSFR product with an assumed SLR value of 1:1 over time. Given the mSFR product has a temporal resolution of $10 \mathrm{~min}$ and a unit of inches per hour (in. $\mathrm{h}^{-1}$ ), the snowfall rates were reduced by a factor of 6 to provide a liquid equivalent every $10 \mathrm{~min}$. Aggregating each $1 \mathrm{~km} \times 1 \mathrm{~km}$ mSFR liquid equivalent value through the duration of each of the cases provides a spatially uniform estimated total liquid equivalent with a higher spatial resolution than interpolated liquid equivalent from COOP stations. Snowfall accumulations for the 21 cases were matched as closely as possible using the available data from NOHRSC. For example, if a case lasted for $31 \mathrm{~h}$, a 24 - and 6-h snowfall accumulation file were aggregated rather than using a 48-h accumulation to better represent the snowfall accumulation for the specific case. The snowfall accumulation data were then reprojected and interpolated to match the projection and resolution of the mSFR product. The ratio of the snowfall accumulation and the derived mSFR total liquid equivalent resulted in a high-resolutionderived SLR estimate. To combat unrealistic values, the minimum thresholds in Roebber et al. (2003) were incorporated to determine SLR values for locations that received at least $50.8 \mathrm{~mm}$ (2.0in.) and $2.8 \mathrm{~mm}$ (0.11 in.) of snowfall accumulation and derived total liquid equivalent, respectively. The derived SLR values were than compared to the 30-yr SLR climatology from Baxter et al. (2005) to validate the results. Furthermore, given the limited temporal extent of the data within this study [i.e., January-April 2018; see Table 1 in Harkema et al. (2019) for specific dates/times], the derived SLR values are not partitioned by month or geographic location compared to the SLR climatology from Baxter et al. (2005).

\section{c. Assignment of SLR, snowfall totals, and snowfall rates at the location of GLM flashes}

A maximum distance threshold of $0.15^{\circ}$ latitude and longitude $(\sim 16 \mathrm{~km})$ was implemented to determine the snowfall rate (i.e., mSFR pixels) in proximity to each GLM group. Given the GLM flash locations are a weighted average, the snowfall rate(s) in proximity of the GLM groups were also averaged during the GLM flash matchup process of the TDA, thus creating a dataset more representative of the environment in which TSSN occurred. To align with the most likely SLR value (i.e., peak of overall SLR distribution) from Baxter et al. (2005) a SLR value of 10:1 was used to compute snowfall rates compared to the other ratio options (i.e., 1:1, 18:1, 35:1) within AWIPS. Snowfall accumulations and SLR values for TSSN flashes observed by GLM were determined using the same methodology as described above. Furthermore, the snowfall accumulations used to derive the highresolution SLR values were used for all snow accumulation analysis.

Compared to the mSFR values, the product of the derived SLR value and the snowfall rate (assuming a 1:1 SLR) for each of the TSSN flashes detected by GLM represents a more realistic estimate of snowfall rates because it considers nonuniform SLR values. Unless otherwise stated, the 2214 TSSN flashes with an mSFR pixel count $\geq 700$ pixels from Harkema et al. (2019) were used for all TSSN flash analysis. Furthermore, 
TSSN categories of no NLDN, NLDN, IC-only, tower, and nontower were examined with respect to snowfall rates, totals, and ratios to quantify possible differences between the categories. To matchup with a GLM flash, NLDN flashes must occur within \pm 1 s of the start and end times of a GLM flash and occur within the larger of two distances thresholds (i.e., $50 \mathrm{~km}$ or the square root of the GLM flash area; Harkema et al. 2019). The TSSN categories were defined as follows:

1) No NLDN: GLM flashes that did not spatially and temporally matchup with NLDN flashes.

2) NLDN: GLM flashes that did spatially and temporally matchup with NLDN flashes.

3) IC-only: A subset of category 2 in which GLM flashes only matchup with NLDN IC flashes

4) Tower: A subset of category 2 in which GLM flashes are associated with at least one NLDN CG flash and the first CG flash occurred within $500 \mathrm{~m}$ of a tall human-made structure like an antenna or wind turbine.

5) Nontower: A subset of category 2 where the first matchup NLDN CG flash occurred beyond $500 \mathrm{~m}$ of a tall human-made structure.

Differentiating these quantities provides in-depth understanding of the characteristics of IC and CG TSSN, and may also allow one to separate flashes from tall human built objects and naturally occurring lightning (Bech et al. 2013; Warner et al. 2014; Kingfield et al. 2017; Schultz et al. 2018).

\section{Results}

\section{a. High-resolution SLR values}

Figure 2 demonstrates the comparison of the Baxter et al. (2005) SLR climatology (Fig. 2a) and overall distribution of the derived SLR values. Visually, the two datasets are similar and both tail off toward larger SLR values. Given the values within the SLR climatology in Baxter et al. (2005) were unknown, direct comparison between the two distributions was limited. However, using the same statistical metrics in Baxter et al. (2005) (i.e., mean, median, 25th percentile, and 75th percentile), the two distributions could be compared in a limited extent (Table 1). For example, a mean SLR of 14.52 was found, approximately $7 \%$ larger than that found in Baxter et al. (2005). This represented the largest percent difference of the four statistical metrics examined in the comparison. Given the small relative differences, our SLR estimate dataset could be used, rather when COOP SLR values, to demonstrate possible connections/patterns between specific SLR values and the existence of

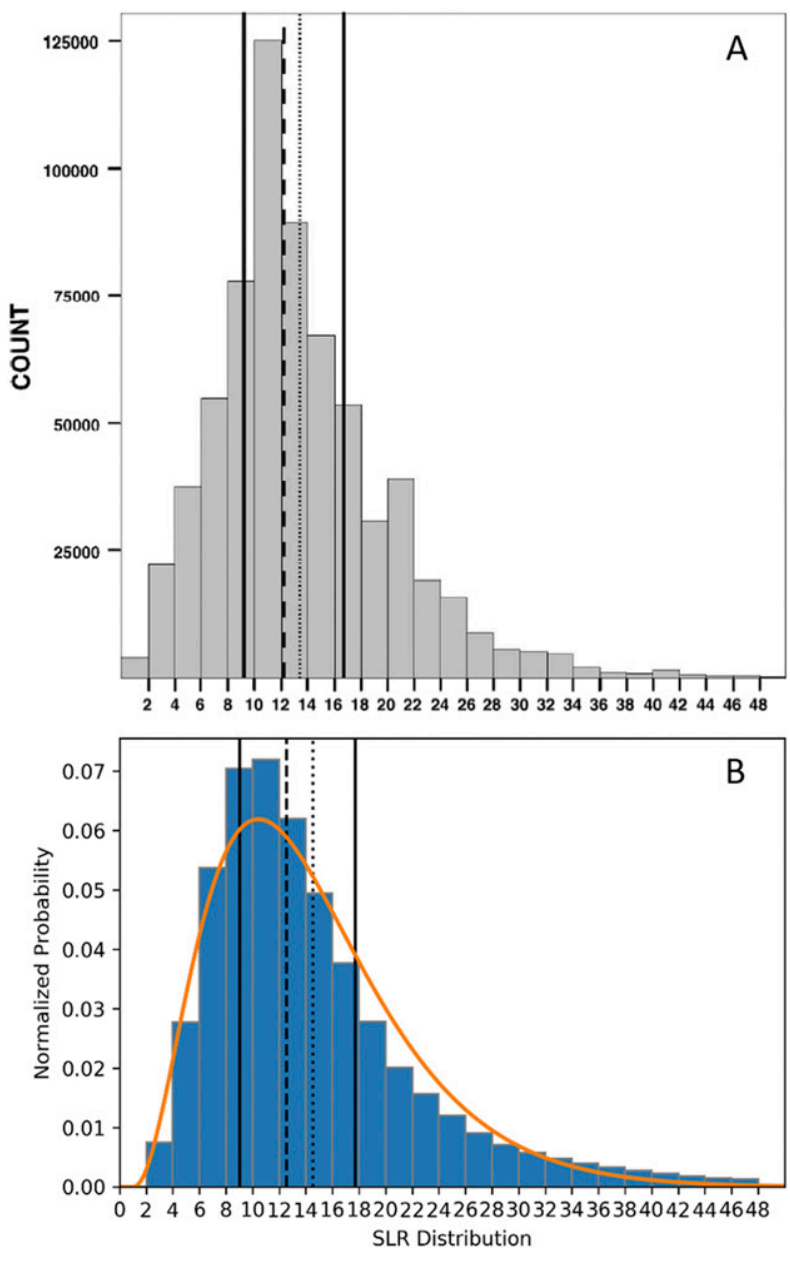

FIG. 2. SLR value distributions from (a) Baxter et al. (2005) (Fig. 9) and (b) derived SLR value estimates. The long dashed line represents the median, the short dashed line represents the mean, and the solid lines represent the 25 th and 75 th percentiles. The orange line in (b) represents the best-fit gamma function for the derived SLR value distribution.

different types of TSSN (e.g., CG versus IC, tower versus nontower).

\section{b. SLR and TSSN}

Of the 2214 TSSN flashes observed by GLM, 1194 of them are associated with derived SLR values and the remaining were associated with snowfall and/or total liquid equivalent measurements below the minimum thresholds in Roebber et al. (2003). The mean and median SLR values associated with TSSN were 12.81 and 11.14 , respectively (Table 2 ). Further, there were nearly twice as many TSSN occurrences in the 8:1-10:1 SLR bins as in the next most common SLR bin (Fig. 3a). This suggests that TSSN was more likely to occur in the lower portion of the medium ratio bin (i.e., 8:1-12:1) from Colle et al. (2014) and were associated with medium to 
TABLE 1. Comparison of SLR values.

\begin{tabular}{lcccc}
\hline \hline \multicolumn{1}{c}{ Methodology } & Mean & Median & $\begin{array}{c}\text { 25th } \\
\text { percentile }\end{array}$ & $\begin{array}{c}\text { 75th } \\
\text { percentile }\end{array}$ \\
\hline Baxter et al. (2005) & 13.53 & 12.14 & 9.26 & 16.67 \\
Derived SLR estimate & 14.52 & 12.57 & 9.05 & 17.71 \\
Difference & -0.99 & -0.43 & 0.21 & -1.04 \\
Percent difference & $-7.05 \%$ & $-3.48 \%$ & $2.29 \%$ & $-6.05 \%$ \\
\hline
\end{tabular}

heavily rimed ice crystals or light rimed compact habits (e.g., plates, needles, graupel, bullets). The discrepancy between the peak and the average SLR values resulted from relatively high derived SLR values $(>25)$ skewing the results. In fact, the skewness and kurtosis of the TSSN SLR distribution was 1.95 and 5.52, respectively. Suggesting that the distribution (Fig. 3a) was skewed farther to the left and more peaked compared to the overall derived SLR distribution; implying that TSSN favors ice crystals that are associated with lower SLR values (Fig. 2b). The fitted gamma function parameters for the TSSN SLR values (orange line, Fig. 3a) were $\alpha=3.45, \beta=2.93$, and location $=2.70$. Using the Mann-Whitney-Wilcoxon two-sided test, for this and all other comparisons hereafter, and taking a random sample of the overall derived SLR values $(N=1194)$ and comparing them to the TSSN SLR distribution resulted in a statistically significant $(p<0.01)$ difference with a $p$ value of $1.26 \times 10^{-7}$. Comparing the SLR values associated with tower TSSN flashes $(N=$ $225)$ to nontower TSSN flashes $(N=474)$ and IC-only TSSN flashes $(N=187)$ detected by GLM resulted in statistically significant $(p<0.05)$ differences with $p$ values of 0.011 and $8.95 \times 10^{-4}$, respectively (Fig. 3b). In fact, tower TSSN flashes observed by GLM have the highest median SLR value (12.89) and the IC-only TSSN flashes have the lowest median SLR value (10.22; Table 3). Therefore, tower TSSN flashes observed by GLM were more likely to occur in a snowfall regime that was associated with higher/lower values in the medium/high ratio bin from Colle et al. (2014) (i.e., 10:1-15:1). Even though the individual distributions in Fig. 3 are statistically different they are highly overlapped with each other and would be worth investigating with in situ observations to provide more insight into these results. Assuming the tower TSSN flashes observed by GLM occurred during the mature phase of cyclogenesis, it can be inferred that tower TSSN flashes, on median, were more likely to transpire within light-to-moderately rimed dendritic and plate snowfall (Figs. 6 and 11 in Colle et al. 2014). Therefore, it can be inferred that the amount of supercooled water necessary for tower TSSN could be less than the necessary amount for nontower and IC-only TSSN detected by GLM and that the presence of a tall human-built structure encourages TSSN to be initiated in lower electric fields where it may have not otherwise occurred. These inferences should be considered for future investigation.

\section{c. Snowfall rates in TSSN}

Even though SLR values play a major role in estimating snowfall rates and can vary drastically depending on where an observer is located in the snowband, the mSFR product does not currently have the capacity to quantitatively estimate the correct SLR value and assumes a uniform SLR value. Therefore, assuming a constant 10:1 SLR value, the snowfall rates from the MSFR product and associated with areas of TSSN $(N=2214)$ were approximately Gaussian distributed (orange line; Fig. 4a). On average, TSSN flashes occurred when snowfall rates were $1.73 \mathrm{~cm} \mathrm{~h}^{-1}\left(0.68 \mathrm{in} . \mathrm{h}^{-1}\right)$ (Table 2). Despite the uniform SLR limitation, the mSFR product can estimate snowfall rates (SLR $=10: 1)$, up to $5.08 \mathrm{~cm} \mathrm{~h}^{-1}$ $\left(2.00 \mathrm{in} . \mathrm{h}^{-1}\right)$, the maximum snowfall rate that TSSN was associated with was $4.14 \mathrm{~cm} \mathrm{~h}^{-1}\left(1.63 \mathrm{in.} \mathrm{h}^{-1}\right)$; thus, TSSN did not occur in the heaviest snowfall rates from an mSFR perspective. This aligned with results from Market and Becker (2009), which showed that the lightning and heaviest rates were offset. On average, CG TSSN flashes observed from GLM $(N=1129)$

TABLE 2. Statistics regarding various physical quantities near the location of TSSN flashes observed by GLM. SLR, snowfall rates, estimated snowfall rates, and snowfall accumulation statistics are based on the overall distribution of these quantities. VII, VIL, and isothermal reflectivity statistics are based on the quantities associated with the 339 TSSN flashes from the case study.

\begin{tabular}{|c|c|c|c|c|}
\hline Variable & Mean & Median & 25 th percentile & 75th percentile \\
\hline Snow-to-liquid ratio & 12.81 & 11.14 & 8.84 & 15.45 \\
\hline Snowfall rates $\left(\right.$ in. $\left.\mathrm{h}^{-1} ; 10: 1\right)$ & 0.68 & 0.66 & 0.53 & 0.81 \\
\hline Estimated snowfall rates (in. $\mathrm{h}^{-1}$ ) & 0.86 & 0.74 & 0.55 & 1.06 \\
\hline Snowfall accumulation (in.) & 9.6 & 9.6 & 7.5 & 11.7 \\
\hline Vertically integrated ice $\left(\mathrm{kg} \mathrm{m}^{-2}\right)$ & 1.70 & 1.50 & 1.20 & 1.88 \\
\hline Vertically integrated liquid $\left(\mathrm{kg} \mathrm{m}^{-2}\right)$ & 0.57 & 0.48 & 0.37 & 0.66 \\
\hline Isothermal reflectivity $\left(-10^{\circ} \mathrm{C} ; \mathrm{dBZ}\right)$ & 21.87 & 22.06 & 19.59 & 24.36 \\
\hline Isothermal reflectivity $\left(-15^{\circ} \mathrm{C} ; \mathrm{dBZ}\right)$ & 21.27 & 21.46 & 19.19 & 23.62 \\
\hline Isothermal reflectivity $\left(-20^{\circ} \mathrm{C} ; \mathrm{dBZ}\right)$ & 20.15 & 20.21 & 18.22 & 22.57 \\
\hline
\end{tabular}



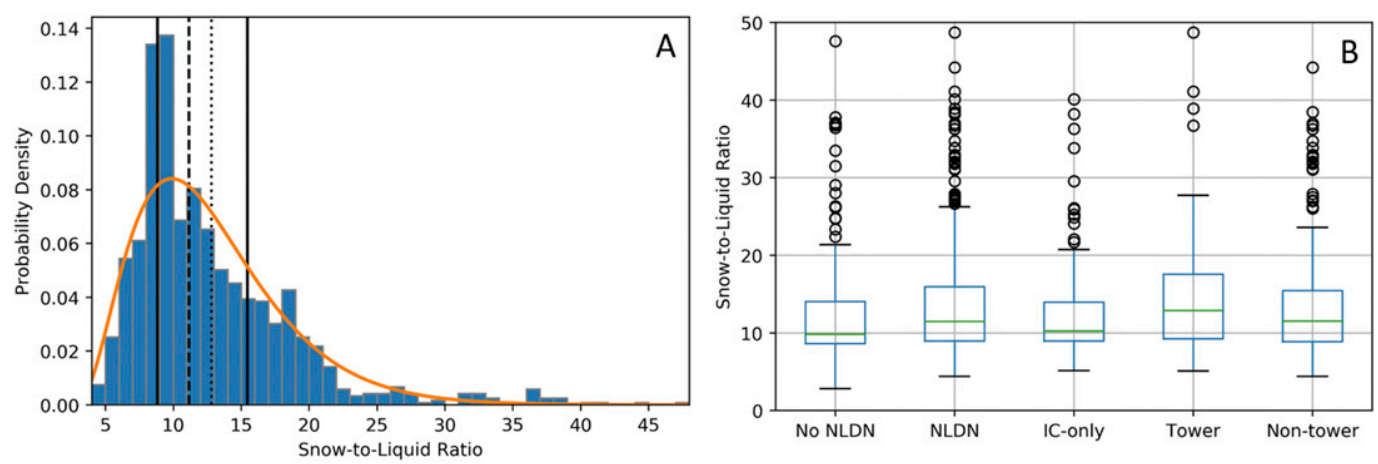

FIG. 3. (a) Distribution of SLR values associated with TSSN. The orange line represents the best-fit gamma function, and the long dashed line represents the median, the short dashed line represents the mean, and the solid lines represent the 25th and 75th percentiles. (b) Box-and-whisker plots of SLR values by TSSN category.

occurred in higher snowfall rates and were statistically different $\left(p=1.92 \times 10^{-15}\right)$ than IC-only TSSN flashes observed by GLM ( $N=580$; Fig. $4 \mathrm{~b})$. Furthermore, tower TSSN flashes observed by GLM $(N=246)$ were associated with the highest mean snowfall rate compared to the other TSSN categories $\left[1.91 \mathrm{~cm} \mathrm{~h}^{-1}\right.$ $\left(0.75 \mathrm{in.}^{-1}\right)$; Table 3]. This corresponds well regarding SLR values and tower TSSN flashes and the fact that the highest snowfall rates tend to be associated with aggregated ice crystals.

Since SLR values are not constant in heavy snowfall, using a constant SLR value can provide inaccurate snowfall rate measurements (Colle et al. 2014). Instead of assuming an SLR of 10:1 as in Fig. 3a, the associated high-resolution SLR values from section $4 \mathrm{~b}$ ) were used to determine the snowfall rates. This increased the mean to $2.18 \mathrm{~cm} \mathrm{~h}^{-1}\left(0.86 \mathrm{in} . \mathrm{h}^{-1}\right)$ and the median to $1.88 \mathrm{~cm} \mathrm{~h}^{-1}$ $\left(0.74 \mathrm{in} . \mathrm{h}^{-1}\right)$ and modified the shape of the distribution from Gaussian to gamma (Fig. 4c). The gamma distribution seen in Fig. $4 c$ is a result of using derived SLR values, a gamma distribution.

On average, IC-only TSSN flashes occurred in the lowest snowfall rates while the tower TSSN flashes identified by GLM occurred in the highest snowfall rates (Table 2). Estimated snowfall rates for CG TSSN flashes $(N=698)$ were statistically significant $(p<0.01)$ compared to IC-only TSSN flashes $(N=187)$ observed by GLM with a $p$ value of $3.80 \times 10^{-7}$ (Fig. $4 d$ ). When comparing the box and whisker plots in Fig. 4, the overlap between the interquartile ranges between the different distributions was less when a nonuniform SLR value was used (Fig. 4d) compared to when an assumed

TABLE 3. Snowfall characteristics with regards to the different TSSN classifications.

\begin{tabular}{|c|c|c|c|c|c|}
\hline Characteristic & TSSN category & Mean & Median & 25 th percentile & 75th percentile \\
\hline \multirow[t]{5}{*}{ Snow-to-liquid ratio } & No NLDN & 12.09 & 9.80 & 8.60 & 14.04 \\
\hline & NLDN & 13.11 & 11.47 & 8.94 & 15.96 \\
\hline & IC-Only & 12.31 & 10.22 & 9.86 & 13.97 \\
\hline & Tower & 14.13 & 12.89 & 9.25 & 17.57 \\
\hline & Nontower & 12.95 & 11.50 & 8.87 & 15.45 \\
\hline \multirow[t]{5}{*}{ Snowfall rate $\left(\right.$ in. $\left.\mathrm{h}^{-1} ; 10: 1\right)$} & No NLDN & 0.60 & 0.57 & 0.47 & 0.71 \\
\hline & NLDN & 0.70 & 0.68 & 0.56 & 0.83 \\
\hline & IC-Only & 0.64 & 0.63 & 0.52 & 0.75 \\
\hline & Tower & 0.75 & 0.74 & 0.62 & 0.87 \\
\hline & Nontower & 0.73 & 0.70 & 0.58 & 0.88 \\
\hline \multirow[t]{5}{*}{ Estimated snowfall rate (in. $\mathrm{h}^{-1}$ ) } & No NLDN & 0.72 & 0.60 & 0.43 & 0.86 \\
\hline & NLDN & 0.92 & 0.81 & 0.59 & 1.12 \\
\hline & IC-Only & 0.77 & 0.65 & 0.49 & 0.94 \\
\hline & Tower & 1.02 & 0.92 & 0.68 & 1.19 \\
\hline & Nontower & 0.93 & 0.82 & 0.60 & 1.15 \\
\hline \multirow[t]{5}{*}{ Snowfall accumulation (in.) } & No NLDN & 9.5 & 9.4 & 8.4 & 11.3 \\
\hline & NLDN & 9.7 & 9.7 & 7.2 & 11.9 \\
\hline & IC-Only & 9.3 & 9.3 & 6.9 & 11.4 \\
\hline & Tower & 9.4 & 9.3 & 5.7 & 12.0 \\
\hline & Nontower & 10.0 & 9.9 & 7.7 & 12.3 \\
\hline
\end{tabular}



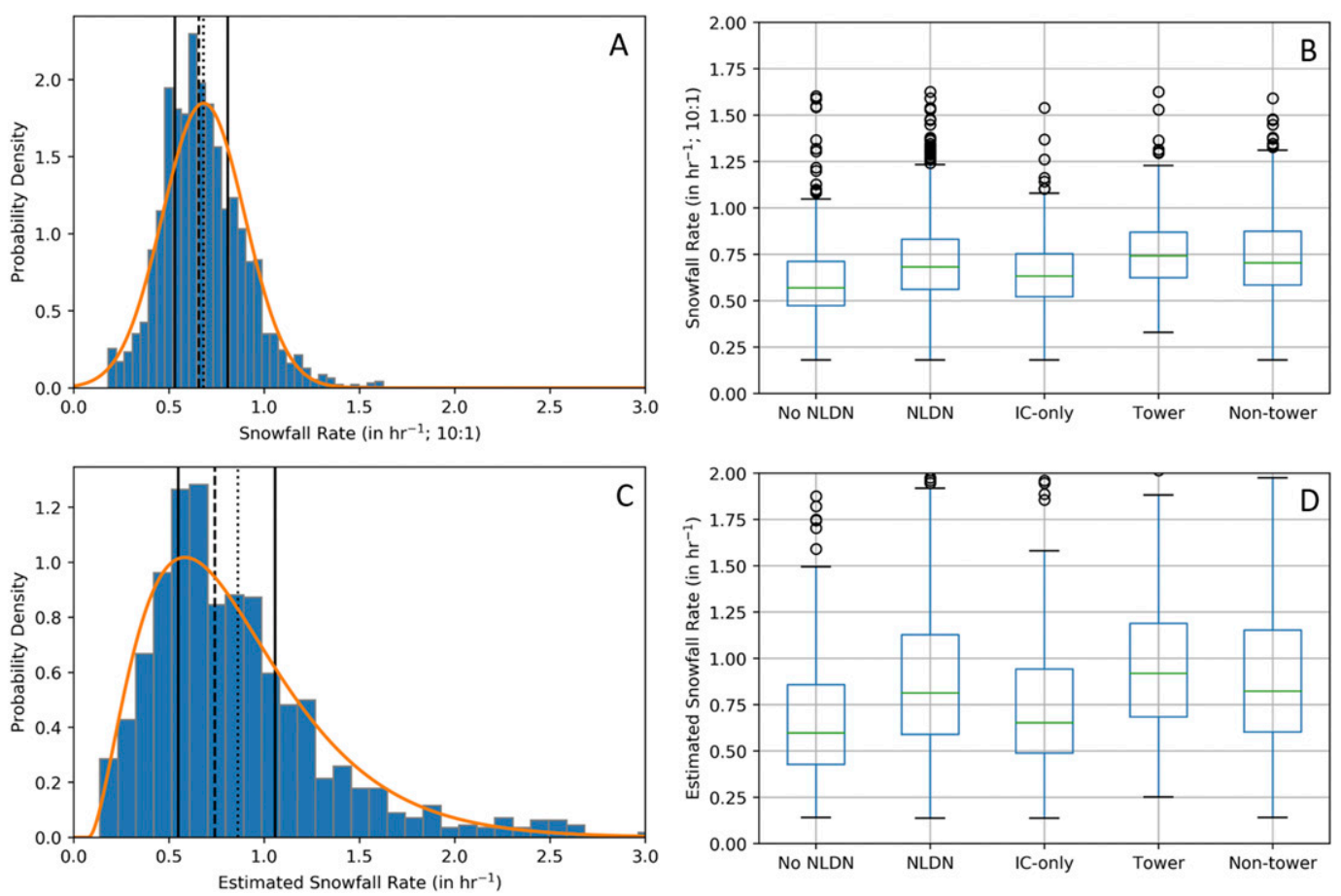

FIG. 4. (a),(c) Distribution of snowfall rates from the mSFR product and estimated snowfall rates derived from the product of mSFR snowfall rates (SLR 1:1) and the derived high-resolution SLR values associated with TSSN. The orange line in (a) represents the best-fit Gaussian function, and the orange line in (c) represents the best-fit gamma function and the long dashed line represents the median, the short dashed line represents the mean, and the solid lines represent the 25 th and 75 th percentiles. (b),(d) Box-and-whisker plots of snowfall rates and estimated snowfall rates by TSSN category.

uniform SLR value was used (Fig. 4b). This provides evidence of a more practical use of defining snowfall rates by a nonuniform SLR value.

\section{d. Snowfall accumulation and TSSN}

Of the 2214 TSSN flashes observed by GLM, 1285 of them were associated with snowfall accumulation. This suggests that TSSN can occur even when accumulating snow was not expected given the possibility that surface and soil temperatures could be too warm for accumulation. To be consistent with the SLR analysis, snowfall accumulations below the Roebber et al. (2003) threshold [i.e., $5.08 \mathrm{~cm}$ (2.0 in.)] were not considered for any snowfall accumulation analysis. Moreover, locations that experience TSSN with accumulating snowfall received a mean and median snowfall total of $24.5 \mathrm{~cm}$ ( $9.6 \mathrm{in}$.) and $24.4 \mathrm{~cm}$ (9.6 in.), respectively (Table 2). A Gaussian distribution can be fitted for locations that experience TSSN and snowfall accumulation (orange line; Fig. 5a). Some locations received approximately $50.8 \mathrm{~cm}$ (20 in.) of total snowfall accumulation when TSSN occurred and were lower than the maximum accumulation for individual cases. This reinforces the results in Crowe et al. (2006) in which they found TSSN does not occur in locations where the largest amount of snowfall accumulation was expected.

The differences in snowfall accumulation distributions between TSSN categories were small and not statistically significant ( $p>0.10$; Fig. 5b). On average, IC-only flashes had the lowest snowfall accumulations at $23.6 \mathrm{~cm}$ (9.3 in.) while CG flashes (not associated with a tower) were only slightly higher at $25.3 \mathrm{~cm}$ (10.0 in., Table 3$)$. Therefore, it can be assumed that the lightning type classification (IC versus CG) has little to no correlation with potential snowfall accumulation. In contrast, the differences in maximum snowfall accumulation associated with IC-only TSSN flashes [i.e., $46.6 \mathrm{~cm}$ (18.3 in.)] compared to the other TSSN categories were less than $5.1 \mathrm{~cm}$ ( $2.0 \mathrm{in}$.). The small differences between the TSSN categories were likely a result of 1) the large difference in the temporal scale of lightning flashes compared to the synoptic scale (from $10^{-1}$ to $10^{0}$ versus $10^{5} \mathrm{~s}$; Rakov and Uman 2006; Martin 2006, p. 60) and 2) the hypothesis that synoptic systems that have the ability of producing TSSN inherently have the ability of producing copious amounts of snowfall accumulation. 

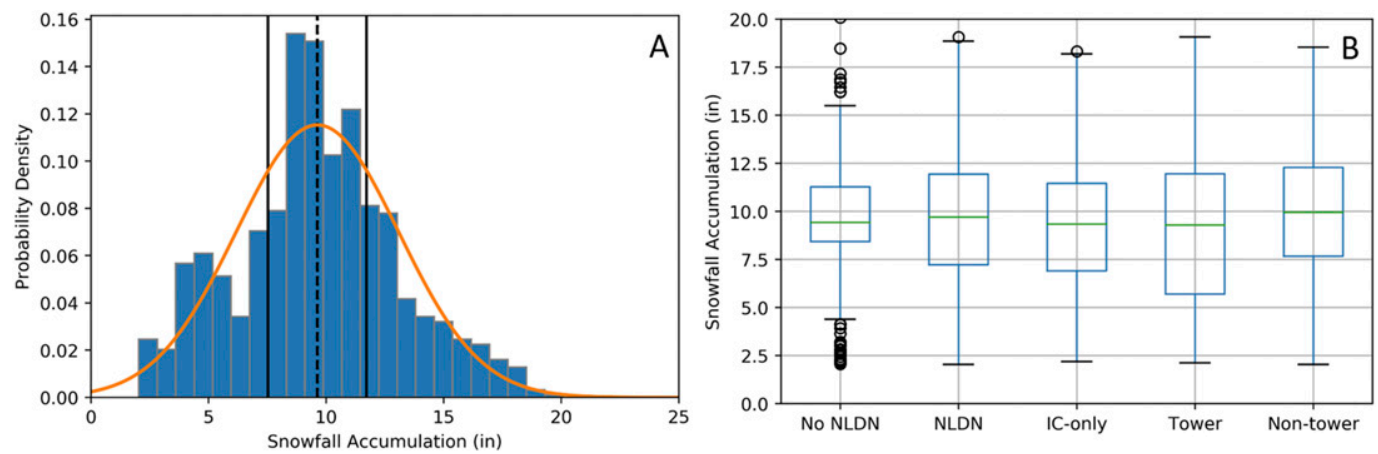

FIG. 5. (a) Distribution of snowfall accumulations associated with TSSN. The orange line represents the best-fit Gaussian function, and the long dashed line represents the median, the short dashed line represents the mean, and the solid lines represent the 25 th and 75 th percentiles. (b) Box-and-whisker plots of snowfall accumulation by TSSN category.

\section{e. 13-17 April 2018 blizzard case study}

\section{1) SYNOPTIC OVERVIEW}

To further characterize and understand the storm and microphysical characteristics as well as potential predictability of TSSN, the 13-17 April 2018 blizzard (i.e., case 21 from Harkema et al. 2019) was examined in greater detail. A mature cyclone developed at 1200 UTC 13 April 2018 along the eastern Kansas-Nebraska border with a surface pressure of $988 \mathrm{hPa}$. At this time, north-central South Dakota started to see widespread snowfall. At 1200 UTC 14 April, the snow became more widespread shifting southeast with surface temperatures at or below $0^{\circ} \mathrm{C}$. During this time, GLM was observing widespread lightning over central Iowa where surface temperatures were a few degrees above $0^{\circ} \mathrm{C}$. Then, 12 hours later, the majority of snowfall was occurring in the upper-left quadrant of the cyclone $(1004 \mathrm{hPa})$ with snowfall rates exceeding $5.08 \mathrm{~cm} \mathrm{~h}^{-1}$ $\left(2.0 \mathrm{in} . \mathrm{h}^{-1}\right)$ in Wisconsin. The system continued to track across the northern half of CONUS and eventually moved up the East Coast of the United States at which point lake-enhanced snow began to fall over the Great Lakes region. Approximately, 22-76 cm ( $~ 9-30$ in.) of accumulated snowfall occurred in part because of the slow progression of this system (Fig. 6a).

This case was chosen because of the large geographic coverage of the case, large number of GLM flashes, and the synoptic and mesoscale regime to the northwest of the cyclone center. MRMS data (i.e., VII, VIL, and isothermal reflectivity) was limited to 13 April 2018 for this event. For the analyses of the MRMS variables relative to the TSSN activity, we defined a smaller domain (from $40^{\circ}$ to $48^{\circ} \mathrm{N}$ latitude and from $100^{\circ}$ to $90^{\circ} \mathrm{W}$ longitude, black box in Fig. 6) that included a majority of the TSSN flashes for this event.

\section{2) SNOWfall ACUMULATIONS, LIQUID EQUIVALENTS, AND SNOW-LIQUID RATIOS}

The highest snowfall accumulations (reds and oranges) and mSFR liquid equivalent (purples) occurred in Wisconsin and Michigan (Figs. 6a,b). Using the minimum thresholds in Roebber et al. (2003), the derived SLR values were found by the ratio of accumulation and liquid equivalent (Fig. 6c). In contrast, Fig. 6d depicts linearly interpolated SLR derived from COOP station data. Comparing the derived and COOP SLR values it becomes evident that the derived SLR depicts smallerscale features that were missed by the COOP SLR. For example, in southwestern Minnesota, the COOP SLR depicts two stations with relatively high SLR values (bright yellows) and the derived SLR depicts an arch of higher SLR (lime green to yellow) in the same locations. This suggests that the derived SLR values have the capacity to identify mesoscale phenomena that were missed due to the limits of the COOP observing system. In contrast, there were also major discrepancies in SLR values in western Nebraska where the derived SLR values demonstrated areas with SLR values exceeding 35:1; observed SLR values in the area ranged from $13: 1$ to $25: 1$. These differences were likely caused by a combination of 1) potential precipitation flag errors in the MRMS portion of the MSFR product and 2) the location of these values being on the periphery of individual radar scan volumes. Even with the discrepancies, the new methodology qualitatively appears to match closely with the observed COOP SLR values but with greater spatial detail.

\section{3) ISOTHERMAL REFLECTIVITY, VERTICALLY} INTEGRATED ICE, AND LIQUID

Previous studies have demonstrated the predictability of lightning in summer convection based on isotherm 

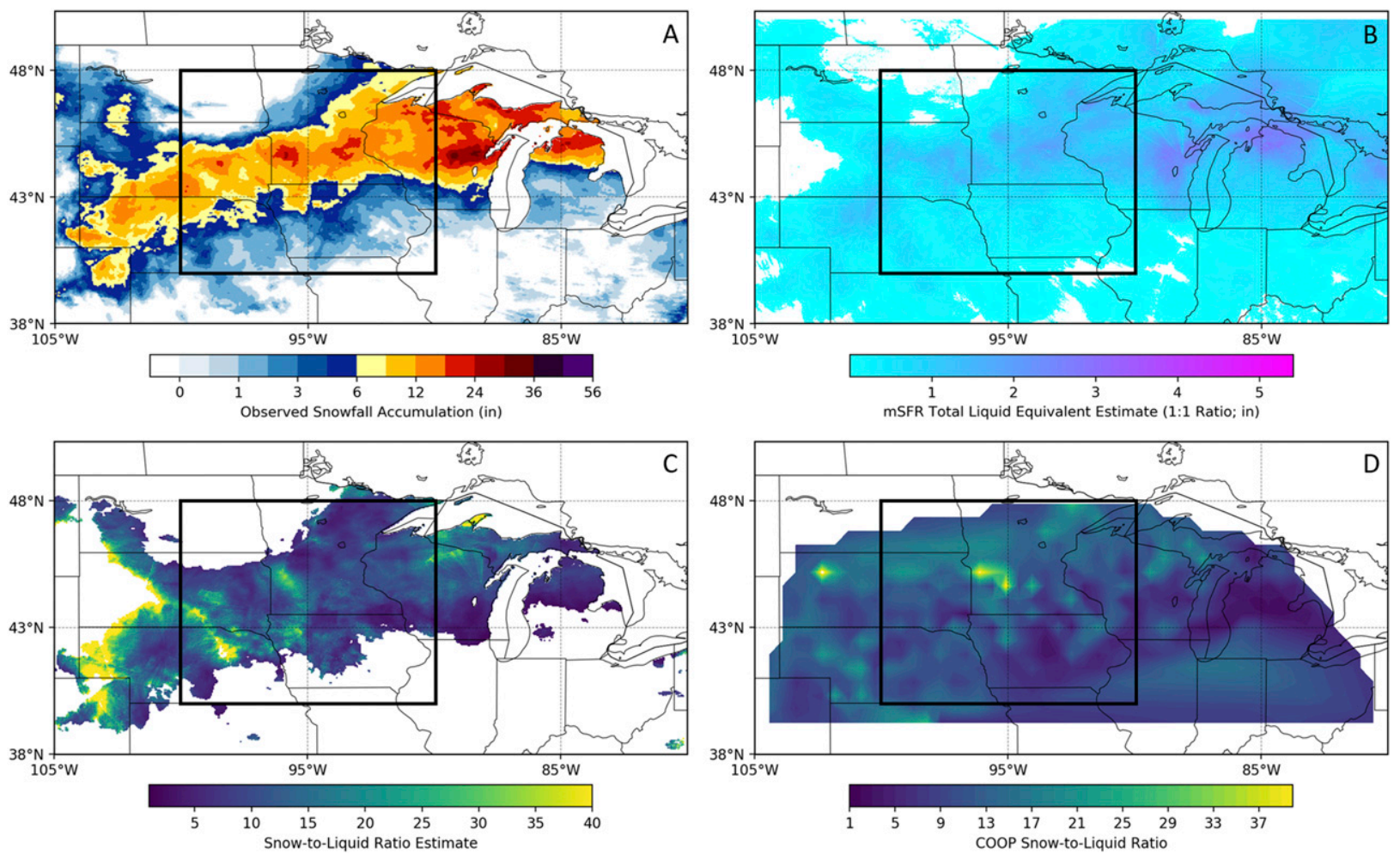

FIG. 6. (a) Total snowfall accumulation, (b) total mSFR liquid equivalent estimation, (c) derived SLR estimate, and (d) linearly interpolated COOP SLR values for the 13-17 Apr 2018 blizzard.

reflectivity, VII, or VIL (e.g., Mosier et al. 2011; Seroka et al. 2012). Therefore, a total of 399 TSSN flashes in this event were paired with MRMS data to determine whether these variables can be used as a predictor of lightning in winter storms. MRMS isothermal (i.e., $-10^{\circ},-15^{\circ},-20^{\circ} \mathrm{C}$ ) reflectivity, VIL, and VII values were assigned to each TSSN flash using the same technique to assign other variables (e.g., snowfall rates) to remain consistent with previous analyses. The mean MRMS isothermal reflectivity values associated with the 339 TSSN flashes observed by GLM for the $-10^{\circ},-15^{\circ}$, and $-20^{\circ} \mathrm{C}$ isotherm levels were 21.87 , 21.27 , and $20.15 \mathrm{~dB} Z$, respectively (Table 2). Figure 7 demonstrates that isothermal reflectivity values associated with TSSN flashes never exceeded $30 \mathrm{~dB} Z$ for this case while VIL and VII quantities remain below $5.00 \mathrm{~kg} \mathrm{~m}^{-2}$. When examining the 339 TSSN flashes, TSSN occurred, on average, in locations with higher VII compared to VIL with mean values of 1.70 and $0.57 \mathrm{~kg} \mathrm{~m}^{-2}$, respectively (Table 2). However, given that MRMS does not detect VII less than $1.00 \mathrm{~kg} \mathrm{~m}^{-2}$ these results were inconclusive and should be investigated further. Future work could include satellitebased radar or individual Level-III radar data for more comprehensive results. However, these results do suggest that regions that experience snowfall and higher MRMS VII values were more likely to experience TSSN than other regions within the snowband.

Contrasting the MRMS variables by the TSSN categories allowed for a greater understanding of the characteristics necessary for different TSSN types (i.e., IC versus $\mathrm{CG}$ ). Figure 8 depicts isothermal reflectivity at the $-10^{\circ}$ and $-20^{\circ} \mathrm{C}$ isotherm levels, VII, and VIL. At both isotherm levels, IC-only TSSN flashes occurred in

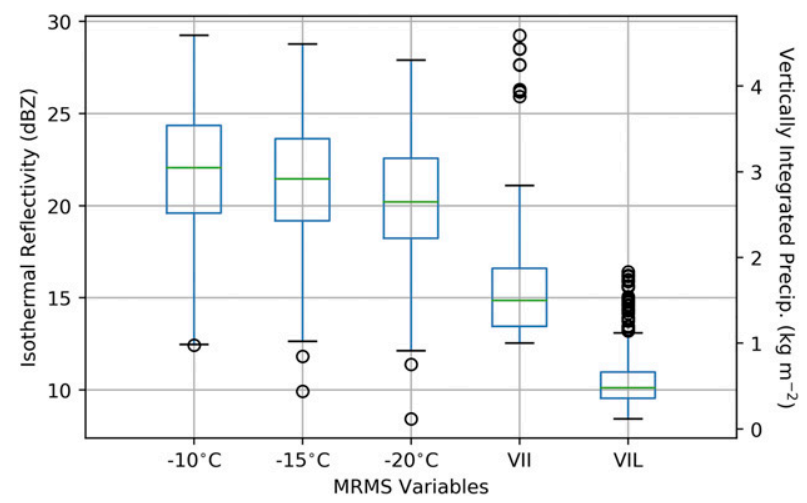

FIG. 7. Box-and-whisker plot for MRMS-derived isothermal reflectivity, VII, and VIL values associated with 339 TSSN flashes observed by GLM that overlap with MRMS on 13 Apr 2018. 

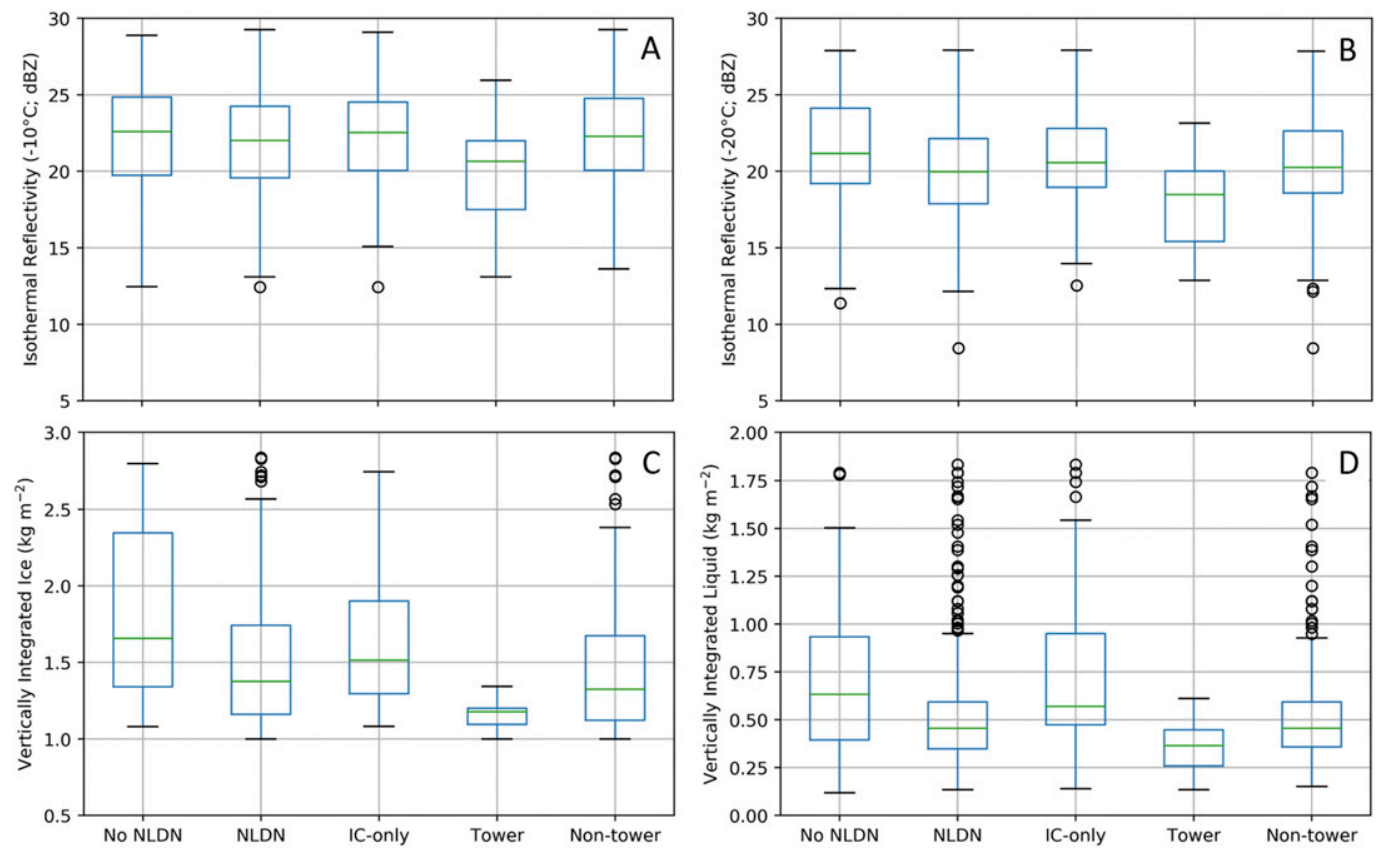

FIG. 8. Box-and-whisker plots for 339 TSSN flashes that overlapped with MRMS on 13 Apr 2018 regarding the different TSSN categories (i.e., no NLDN, NLDN, IC-only, tower, and nontower) for (a) $-10^{\circ} \mathrm{C}$ isothermal reflectivity, (b) $-20^{\circ} \mathrm{C}$ isothermal reflectivity, (c) VII, and (d) VIL.

higher reflectivity compared to CG TSSN flashes (i.e., nontower and tower; Figs. 8a,b). Comparing IC-only $(N=57)$ and tower $(N=59)$ TSSN flashes identified by GLM resulted in the two distributions being different at a statistically significant 0.01 confidence level for the $-10^{\circ} \mathrm{C}$ $\left(p=3.05 \times 10^{-5}\right)$ and $-20^{\circ} \mathrm{C}\left(p=1.32 \times 10^{-5}\right)$ isotherm levels, respectively. These two distributions were also different at a statistically significant 0.01 confidence level for VII $\left(p=7.67 \times 10^{-4}\right)$ and VIL $\left(p=3.98 \times 10^{-11}\right)$. In fact, tower TSSN flashes have the lowest mean VII $\left(1.17 \mathrm{~kg} \mathrm{~m}^{-2}\right)$ and VIL $\left(0.36 \mathrm{~kg} \mathrm{~m}^{-2}\right)$. Furthermore, IC-only TSSN flashes observed by GLM have the highest median VII and VIL values compared to the other TSSN categories (Figs. 8c,d). Given IC-only flashes occur in the lowest SLR values suggests that the high median VII for IC-only was caused by relatively dense ice particles that have a large degree of riming caused by higher values of supercooled water.

\section{Discussion}

Examining the 21 snowfall cases from Harkema et al. (2019), it appeared as though TSSN occurred more often on the equator side of the major axis of the snowband regardless of orientation and reinforces the results in Market and Becker (2009) and Rauber et al. (2014). Coincidentally, in this same region within the comma head, Colle et al. (2014) determined that the western quadrant experienced little-to-no riming while heavy riming was observed close to the cyclone center. Given how SLR values were determined and the fact a stereomicroscope was not used to identify ice crystal habit in this study, the conceptual theory of preferential ice crystal habit and the presence of TSSN cannot be verified. The TSSN SLR results from this study add evidence to the potential relationship between SLR, ice crystal habit, and electrified snowfall. Furthermore, the highresolution-derived SLR values are complimentary to future studies regarding potential ice crystal habit studies of midlatitude wintertime cyclones. However, the derived SLR values were computationally expensive compared to interpolating COOP SLR values. As a result, future studies should use the COOP SLR values as a first guess then explore the derived SLR values for detailed analysis.

Even though this study was temporally limited compared to Crowe et al. (2006), the results were similar in suggesting that TSSN does not occur in the highest snowfall accumulations of a synoptic system. Crowe et al. (2006) found that TSSN tend to be associated with events with accumulation totals greater than $15 \mathrm{~cm}$ (5.9 in.) and approximately represents the 36 th percentile in the TSSN snowfall accumulation distribution. The discrepancy between these two results was likely based on the TSSN identification process (i.e., sound audibility versus optical light). 
A

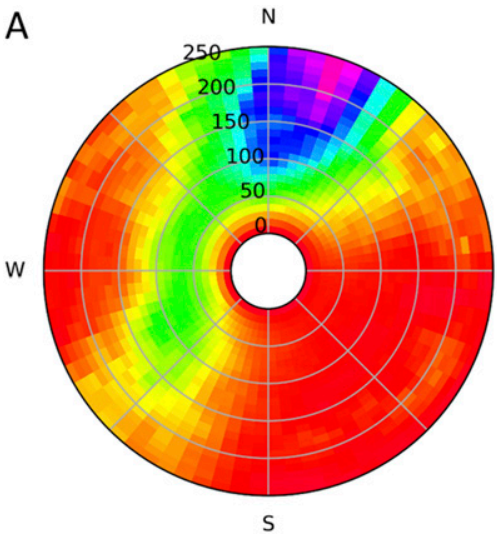

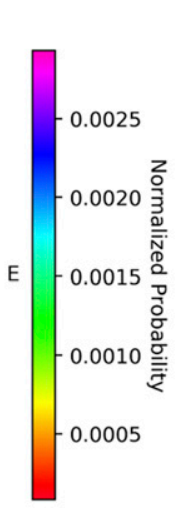

B

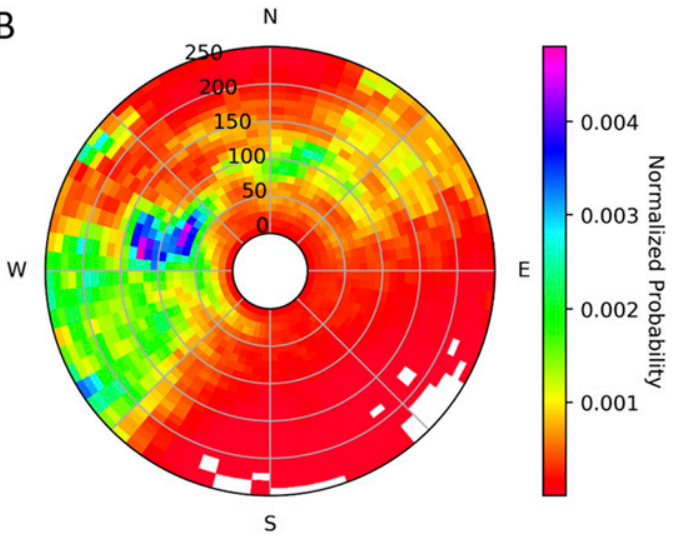

FIG. 9. Polar plots of frequency of snowfall rates greater than $4.44 \mathrm{~cm} \mathrm{~h}^{-1}\left(1.75 \mathrm{in.} \mathrm{h}^{-1}\right)$ for (a) all TSSN flashes observed by GLM and (b) TSSN flashes observed by GLM for the 13-17 Apr 2018 blizzard.

Using the space-based GPM Ku-band radar, Adhikari and Liu (2019) found most TSSN events had a maximum radar reflectivity $>30 \mathrm{~dB} Z$ at temperatures $<-10^{\circ} \mathrm{C}$. In contrast, using higher-resolution composited MRMS data, it was found lower isothermal reflectivity for TSSN activity, with values between 25 and $30 \mathrm{dBZ}$ for all categories. As additional space-based radars become available, studies examining TSSN will be able to directly compare results to those from Adhikari and Liu (2019) and provide further insight into the results from this study. Matching the results of Market and Becker (2009), we found that TSSN did not typically occur within the highest reflectivity or the highest snowfall rates. Additionally, since there are large spatial areas of reflectivity between 10 and $30 \mathrm{dBZ}$ in snowstorms (e.g., Thompson et al. 2014), isothermal reflectivity values did not discriminate well between regions with TSSN activity and without.

In contrast, the isothermal reflectivities associated with summertime convective storms are known to be higher compared to those in winter storms. Mosier et al. (2011) found that using $30 \mathrm{dBZ}$ at the $-15^{\circ} \mathrm{C}$ or the $-20^{\circ} \mathrm{C}$ isotherm were the best predictor of lightning and is higher compared to the $25 \mathrm{dBZ}$ at the same isotherm levels in Seroka et al. (2012). The isotherm reflectivity results in this study are more aligned with those in Seroka et al. (2012) given the isothermal reflectivities associated with TSSN never exceeded $30 \mathrm{dBZ}$. As for VII, it was found that IC-only flashes had higher VII values compared to CG flashes (i.e., Tower and nontower) and is opposite compared to the conclusions in Seroka et al. (2012). Additionally, the mean VII values associated with TSSN were between the 40th and 45th percentile for VII results in Mosier et al. (2011). These comparisons suggest that VII may provide some practicality in predicting TSSN but further research is needed given only 339 TSSN flashes were examined in the VII analysis.

Figure 9a demonstrates the locations of snowfall rates greater than $4.44 \mathrm{~cm} \mathrm{~h}^{-1}\left(1.75 \mathrm{in} . \mathrm{h}^{-1}\right)$ with regards to all TSSN flashes observed by GLM, which results in a mean distance between the heaviest snowfall rates and TSSN of $131 \pm 65 \mathrm{~km}$. In contrast, Fig. 9b depicts the distribution of snowfall rates with regards to TSSN flashes detected by GLM for the 13-17 April 2018 blizzard and suggests that TSSN is more likely to occur east of the heaviest snowfall rates. This is similar to Market and Becker (2009) in which they found that two-thirds of lightning flashes in snowbands occur downstream from the greatest radar reflectivity values. One potential explanation for this is the potential for long drift of snow and ice particles during the descent to the surface resulting in horizontal displacement between locations of strongest vertical motion and heaviest snowfall rates (Rauber et al. 2014; Lackmann and Thompson 2019).

Another plausible explanation for the separation of heaviest snowfall rates and the occurrence of TSSN is the heavy-banded snowfall formation concept model (Fig. 15 in Moore and Graves 2005). Heavy-banded snowfall partially occurs because of a slantwise circulation caused by midlevel frontogenesis and is on the northern extent of conditional symmetric instability. Conceptually, TSSN occurring in this study (i.e., equator side of the major axis of snowbands) and in Market and Becker (2009) (i.e., leading edge of snowband) are within this region. As a proof of concept, mean midlevel (i.e., $850-600 \mathrm{hPa}$ ) frontogenesis derived from the HighResolution Rapid Refresh (HRRR; Alexander et al. 2010; Blaylock et al. 2017) model data were plotted alongside TSSN flashes observed by GLM and demonstrates that TSSN is occurring in regions of higher mean midlevel frontogenesis along the Minnesota-Iowa 


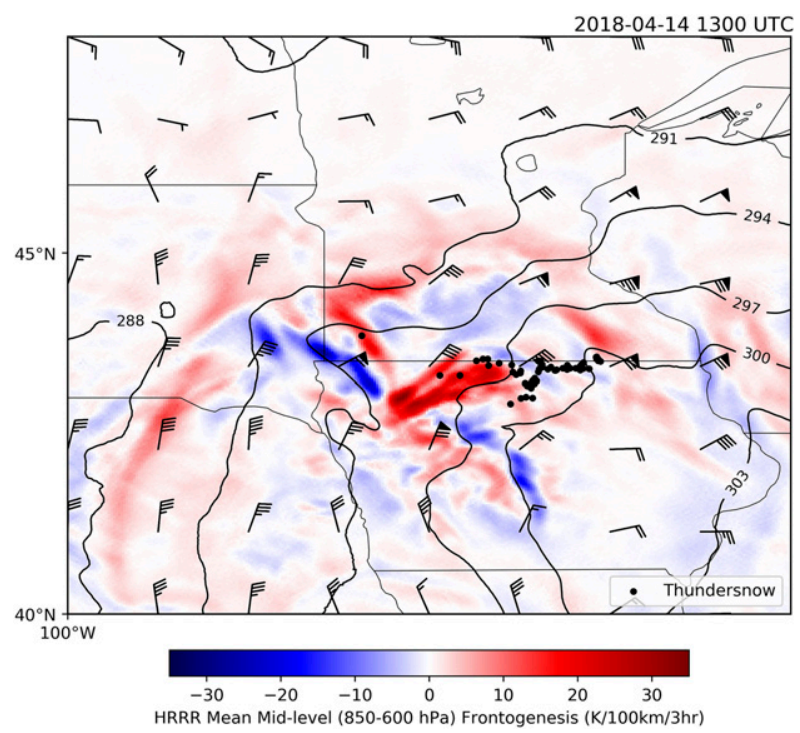

FIG. 10. HRRR-derived mean midlevel (850-600 hPa) frontogenesis at 1300 UTC 14 Apr 2018 overlaid with TSSN flashes observed by GLM (black dots) that occurred between 1300 and 1310 UTC. Wind barbs and black contours represent midlevel (850-600 hPa) bulk shear and potential temperature, respectively.

border (Fig. 10). Therefore, it can be suggested that TSSN occurs in regions where enhanced midlevel frontogenesis exists. However, the examination of this is beyond the scope of this study and warrants future investigation.

Of all the results within this study, the tower TSSN flashes identified by GLM stand out with regards to SLR values, snowfall rates, isothermal reflectivity, VII, and VIL. Tower TSSN flashes occurred in higher snowfall rates and SLR values while also occurring in regions with lower isothermal reflectivity, VIL, and VII compared to nontower and IC-only TSSN flashes. The enhancement of the electric field, caused by the higher snowfall rates and more ice crystal collision (i.e., charge transfer), and the fact that the negative charge center in winter storms are lower cause the dielectric breakdown and is a plausible reason why the frequency of tower flashes are more preferential in winter storms compared to summer convection (Dye et al. 1986; Takahashi et al. 1999). Together, the low values in VII and VIL resulted in further evidence that tower TSSN flashes observed by GLM were more likely to occur in snowfall associated with higher SLR values because dendrites have a low density compared to other ice crystals and do not rime as efficiently (Heymsfield 1972; Colle et al. 2014). Tower TSSN flashes observed by GLM were inferred to occur in lower amounts of supercooled liquid water based on ice crystal habit, degree of riming, and lower values in MRMS VII and VIL compared to nontower and IC
TSSN flashes (Figs. 6, 11 from Colle et al. 2014). However, further study with a large dataset and in situ observations, potentially a field campaign, is needed to quantitatively validate whether tower TSSN flashes require less supercooled liquid water for initiation compared to other forms of TSSN.

\section{Conclusions}

The development of the TDA allows for the objective characterization of TSSN from a GLM perspective and enhances the fundamental understanding of storm and microphysical characteristics associated with electrified heavy snowfall events. Comparing the distribution of SLR values of areas that experienced TSSN to the overall SLR value distribution it was found that the two distributions were different at a statistically significant 0.01 confidence level. On average, TSSN occurred in a SLR value of 12.81 but was more likely to occur between SLR values of 8:1-10:1. This suggests that TSSN was more likely to be associated with ice particles that have some degree of riming. Furthermore, it was found that tower TSSN flashes observed by GLM occurred in the highest median SLR value (12.89) and IC-only TSSN flashes were associated with the lowest median SLR value (10.22). This study also adds further evidence that TSSN does not occur in the highest snowfall rates and occurred within a mean snowfall rate, assuming 10:1 SLR, of $1.73 \mathrm{~cm} \mathrm{~h}^{-1}\left(0.68 \mathrm{in} . \mathrm{h}^{-1}\right)$. Adjusting the snowfall rates to be more aligned with the derived SLR values resulted in a TSSN mean estimated snowfall rate of $2.18 \mathrm{~cm} \mathrm{~h}^{-1}\left(0.86 \mathrm{in} . \mathrm{h}^{-1}\right)$. Tower TSSN flashes occurred in the highest mean snowfall rates [i.e., $1.90 \mathrm{~cm} \mathrm{~h}^{-1}$ (0.75 in. $\left.\mathrm{h}^{-1}\right)$ ]. No statistically significant differences were found when examining the TSSN categories with regards to total snowfall accumulation. During the heavy snowfall cases within Harkema et al. (2019), areas that accumulated at least $2 \mathrm{in}$. of snowfall and experienced TSSN received on average $24.5 \mathrm{~cm}$ (9.6 in.) of snowfall accumulation. This result is based on a single winter season and more analysis and seasons are needed for a comprehensive climatology and characterizations of TSSN events.

The 13-17 April 2018 blizzard was used to examine the potential capability to predict and further characterize TSSN. MRMS VII, VIL, and isothermal reflectivity values were examined in and around the Iowa-Minnesota-South Dakota border region. In this case study, the mean $-10^{\circ},-15^{\circ},-20^{\circ} \mathrm{C}$ isothermal reflectivities associated with TSSN flashes observed by GLM were 21.87, 21.27, and $20.15 \mathrm{dBZ}$, respectively. TSSN flashes observed by GLM were also associated with mean values of 1.70 and $0.57 \mathrm{~kg} \mathrm{~m}^{-2}$ for VII and 
VIL, respectively. Comparing the MRMS variables for the different TSSN categories, it was found that tower TSSN flashes and IC-only TSSN flashes detected by GLM were statistically significant for isothermal reflectivity, VII, and VIL $(p<0.01)$. Furthermore, tower TSSN flashes occurred within the lowest mean isothermal reflectivity, VII, and VIL compared to the other TSSN categories. Societal impacts of heavy snowfall vary by region but the objective characterization of TSSN beyond traditional ground-based observations is a first step to realizing the capability of GLM for winter events. Next steps include further exploration of the microphysical processes, mesoscale processes, and electric field properties that create lightning in snowfall events.

Acknowledgments. This work was directly supported by Dr. Tsengdar Lee of NASA's Research and Analysis Program, Weather Focus Area, as part of the Short-term Prediction Research and Transition (SPoRT) Center at Marshall Space Flight Center. This work was also supported through the NASA-UAH Cooperative Agreement NNM11AA01A. The authors wish to thank Drs. Phillip Bitzer and Geoffrey Stano of UAH for providing support for all things GLM, Dr. Huan Meng of NESIDIS for providing the mSFR product data, and Dr. Kwo-Sen Kuo of NASA GSFC for providing access to the MRMS data. The authors would also like to thank Drs. Kevin Knupp and John Mecikalski of UAH for their continued support. HRRR data were accessed via the University of Utah archive (doi:10.7278/S5JQ0Z5B) courtesy of Brian Blaylock. The authors would also like to thank the three anonymous reviewers for providing valuable insight and suggestions.

\section{REFERENCES}

Adhikari, A., and C. Liu, 2019: Geographical distribution of thundersnow events and their properties from GPM Ku-band radar. J. Geophys. Res. Atmos., 124, 2031-2048, https://doi.org/ 10.1029/2018JD028839.

Alexander, C. R., S. S. Weygandt, T. G. Smirnova, S. Benjamin, P. Hofmann, E. P. James, and D. A. Koch, 2010: High Resolution Rapid Refresh (HRRR): Recent enhancements and evaluation during the 2010 convective season. 25th Conf. on Severe Local Storms, Boulder, CO, Amer. Meteor. Soc., 9.2, https:// ams.confex.com/ams/25SLS/techprogram/paper_175722.htm.

Baxter, M. A., and P. N. Schumacher, 2017: Distribution of singlebanded snowfall in central U.S. cyclones. Wea. Forecasting, 32, 533-554, https://doi.org/10.1175/WAF-D-16-0154.1.

—_, C. E. Graves, and J. T. Moore, 2005: A climatology of snow-to-liquid ratio for the contiguous United States. Wea. Forecasting, 20, 729-744, https://doi.org/10.1175/WAF856.1.

Bech, J., N. Pineda, T. Rigo, and M. Aran, 2013: Remote sensing analysis of a Mediterranean thundersnow and low-altitude heavy snowfall event. Atmos. Res., 123, 305-322, https://doi.org/ 10.1016/j.atmosres.2012.06.021.
Bentley, J. L., 1975: Multidimensional binary search trees used for associative searching. Commun. ACM, 18, 509-517, https:// doi.org/10.1145/361002.361007.

Blaylock, B., J. Horel, and S. Liston, 2017: Cloud archiving and data mining of high-resolution Rapid Refresh forecast model output. Comput. Geosci., 109, 43-50, https://doi.org/10.1016/ j.cageo.2017.08.005.

Carey, L. D., and S. A. Rutledge, 2000: The relationship between precipitation and lightning in tropical island convection: A C-band polarimetric radar study. Mon. Wea. Rev., 128, 2687-2710, https://doi.org/10.1175/1520-0493(2000) $128<2687$ :TRBPAL $>2.0$. CO 2 .

Cherington, M., D. Breed, P. Yarnell, and W. Smith, 1998: Lightning injuries during snowy conditions. Br. J. Sports Med., 32, 333-335, https://doi.org/10.1136/bjsm.32.4.333.

Christian, H. J., and S. J. Goodman, 1987: Optical observations of lightning from a high altitude airplane. J. Atmos. Oceanic Technol., 4, 701-711, https://doi.org/10.1175/1520-0426(1987) 004<0701:OOOLFA $>2.0 . \mathrm{CO} ; 2$.

Cifelli, R., N. Doesken, P. Kennedy, L. D. Carey, S. A. Rutledge, C. Gimmestad, and T. Depue, 2005: The community collaborative rain, hail, and snow network: Informal education for scientists and citizens. Bull. Amer. Meteor. Soc., 86,1069-1078, https://doi.org/10.1175/BAMS-86-8-1069.

Colle, B. A., D. Stark, and S. E. Yuter, 2014: Surface microphysical observations within East Coast winter storms on Long Island. Mon. Wea. Rev., 142, 3126-3146, https://doi.org/ 10.1175/MWR-D-14-00035.1.

Crowe, C., P. Market, B. Pettegrew, C. Melick, and J. Podzimek, 2006: An investigation of thundersnow and deep snow accumulations. Geophys. Res. Lett., 33, L24812, https://doi.org/ 10.1029/2006GL028214.

Cummins, K. L., and M. J. Murphy, 2009: An overview of lightning locations systems: History, techniques, and data uses with an in-depth look at the U.S. NLDN. IEEE Trans. Electromagn. Compat., 51, 499-518, https://doi.org/10.1109/ TEMC.2009.2023450

Curran, J. T., and A. D. Pearson, 1971: Proximity soundings for thunderstorms with snow. Preprints, Seventh Conf. on Severe Local Storms, Kansas City, MO, Amer. Meteor. Soc., 118-119.

Deierling, W., J. Latham, W. A. Petersen, S. M. Ellis, and H. J. Christian, 2005: On the relationship of thunderstorm ice hydrometeor characteristics and total lightning measurements. Atmos. Res., 76, 114-126, https://doi.org/10.1016/ j.atmosres.2004.11.023.

Dolif Neto, G., and Coauthors, 2009: A comparison of two cases of low-latitude thundersnow. Atmósfera, 22, 315-330.

Dye, J. E., and Coauthors, 1986: Early electrification and precipitation development in a small, isolated Montana cumulonimbus. J. Geophys. Res., 91, 1231-1247, https://doi.org/10.1029/ JD091ID01P01231.

Ferraro, R., and Coauthors, 2018: Snowfall rates from satellite data help weather forecasters. Eos, Trans. Amer. Geophys. Union, 99, https://doi.org/10.1029/2018EO096715.

Goodman, S. J., and Coauthors, 2013: The GOES-R Geostationary Lightning Mapper (GLM). Atmos. Res., 125-126, 34-49, https://doi.org/10.1016/j.atmosres.2013.01.006.

Gremillion, M. S., and R. E. Orville, 1999: Thunderstorm characteristics of cloud-to-ground lightning at the Kennedy Space Center, Florida: A study of lightning initiation signatures as indicated by the WSR-88D. Wea. Forecasting, 14, 640-649, https://doi.org/10.1175/1520-0434(1999)014<0640: TCOCTG $>2.0 . \mathrm{CO} ; 2$. 
Harkema, S. S., E. B. Berndt, C. J. Schultz, and P. M. Bitzer, 2019: Geostationary lightning mapper flash characteristics of electrified snowfall events. Wea. Forecasting, 34, 1571-1585, https://doi.org/10.1175/WAF-D-19-0082.1.

Herschel, A., 1888: Lightning in snowstorms. Quart. J. Roy. Meteor. Soc., 14, 222-225, https://doi.org/10.1002/QJ.4970146706.

Heymsfield, A., 1972: Ice crystal terminal velocities. J. Atmos. Sci., 29, 1348-1357, https://doi.org/10.1175/1520-0469(1972)029<1348: ICTV>2.0.CO;2.

Holle, R., R. López, K. Howard, K. Cummins, M. Malone, and E. Krider, 1997: An isolated winter cloud-to-ground lightning flash causing damage and injury in Connecticut. Bull. Amer. Meteor. Soc., 78, 437-441, https://doi.org/10.1175/ 1520-0477(1997)078<0437:AIWCTG > 2.0.CO;2.

Hou, A. Y., and Coauthors, 2014: The Global Precipitation Measurement Mission. Bull. Amer. Meteor. Soc., 95, 701-722, https://doi.org/10.1175/BAMS-D-13-00164.1.

Jayaratne, E., C. Saunders, and J. Hallett, 1983: Laboratory studies of the charging of softhail during ice crystal interactions. Quart. J. Roy. Meteor. Soc., 109, 609-630, https://doi.org/ 10.1002/QJ.49710946111.

Kingfield, D. M., K. M. Calhoun, and K. D. de Beurs, 2017: Antenna structures and cloud-to-ground lightning location: 1995-2015. Geophys. Res. Lett., 44, 5203-5212, https://doi.org/ 10.1002/2017GL073449.

Kumjian, M. R., and W. Deierling, 2015: Analysis of thundersnow storms over northern Colorado. Wea. Forecasting, 30, 14691490, https://doi.org/10.1175/WAF-D-15-0007.1.

Lackmann, G. M., and G. Thompson, 2019: Hydrometeor lofting and mesoscale snowbands. Mon. Wea. Rev., 147, 3879-3899, https://doi.org/10.1175/MWR-D-19-0036.1.

Market, P. S., and A. E. Becker, 2009: A study of lightning flashes attending periods of banded snowfall. Geophys. Res. Lett., 36, L01809, https://doi.org/10.1029/2008GL036317.

—_, C. E. Halcomb, and R. L. Ebert, 2002: A climatology of thundersnow events over the contiguous United States. Wea. Forecasting, 17, 1290-1295, https://doi.org/10.1175/1520-0434(2002) 017<1290:ACOTEO > 2.0.CO;2.

Martin, J. E., 2006: Mid-Latitude Atmospheric Dynamics: A First Course. Wiley, 324 pp.

Meng, H., J. Dong, R. Ferraro, B. Yan, L. Zhao, C. Kongoli, N. Y. Wang, and B. Zavodsky, 2017a: A 1DVAR-based snowfall rate retrieval algorithm for passive microwave radiometers. J. Geophys. Res. Atmos., 122, 6520-6540, https://doi.org/ 10.1002/2016JD026325.

,-- C. Kongoli, R. Ferraro, B. Yan, K. White, E. Berndt, and B. Zavodsky, 2017b: NESDIS snowfall rate product and its applications. JPSS Science Seminar, 41 pp., http://www.jpss.noaa.gov/ assets/pdfs/science_seminars/presentations/SnowfallRate_Meng White_Berndt_2017.pdf.

Miyake, K., T. Suzuki, M. Takashima, M. Takuma, and T. Tada, 1990: Winter lightning on Japan sea coast-lightning striking frequency to tall structures. IEEE Trans. Power Delivery, $\mathbf{5}$, 1370-1376, https://doi.org/10.1109/61.57979.

Molthan, A. L., and W. A. Petersen, 2011: Incorporating ice crystal scattering databases in the simulation of millimeterwavelength radar reflectivity. J. Atmos. Oceanic Technol., 28, 337-351, https://doi.org/10.1175/2010JTECHA1511.1.

Moore, J., and C. Graves, 2005: A process-oriented methodology toward understanding the organization of an extensive mesoscale snowband: A diagnostic case study of 4-5 December 1999. Wea. Forecasting, 20, 35-50, https://doi.org/10.1175/ WAF-829.1.
Mosier, R. M., C. Schumacher, R. E. Orville, and L. D. Carey, 2011: Radar nowcasting of cloud-to-ground lightning over Houston, Texas. Wea. Forecasting, 26, 199-212, https://doi.org/10.1175/ 2010WAF2222431.1.

Nicosia, D. J., and R. H. Grumm, 1999: Mesoscale band formation in three major northeastern United States snowstorms. Wea. Forecasting, 14, 346-368, https://doi.org/10.1175/ 1520-0434(1999)014<0346:MBFITM>2.0.CO;2.

Novak, D. R., J. S. Waldstreicher, L. F. Bosart, and D. Keyser, 2006: A forecast strategy for anticipating cold season mesoscale band formation within eastern U.S. cyclones. Wea Forecasting, 21, 3-23, https://doi.org/10.1175/WAF907.1.

NWS, 2015: NWS Technical Implementation Notice 15-05. NWS, 2 pp., https://www.weather.gov/media/notification/ tins/tin15-05bigrsc_snowfall.pdf.

, 2017: National Weather Service Instruction 10-1305: Observational quality control-general. Surface observing program (land), NWSPD 10-13, 21 pp., https://www.nws.noaa.gov/directives/ sym/pd01013005curr.pdf.

, 2019: What is the Coop Program? NWS, accessed 6 February 2019, https://www.weather.gov/coop/overview.

Paluch, I. R., and J. D. Sartor, 1973: Thunderstorm electrification by the inductive charging mechanism: I. Particle charges and electric fields. J. Atmos. Sci., 30, 1166-1173, https://doi.org/ 10.1175/1520-0469(1973)030<1166:TEBTIC > 2.0.CO;2.

Rakov, V. A., and M. A. Uman, 2006: Lightning: Physics and Effects. 3rd ed. Cambridge University Press, 687 pp.

Rauber, R. M., and Coauthors, 2014: Stability and charging characteristics of the comma head region of continental winter cyclones. J. Atmos. Sci., 71, 1559-1582, https://doi.org/10.1175/ JAS-D-13-0253.1.

Reynolds, S. E., M. Brooks, and M. F. Gourley, 1957: Thunderstorm charge separation. J. Meteor., 14, 426-436, https://doi.org/ 10.1175/1520-0469(1957)014<0426:TCS > 2.0.CO;2.

Roebber, P. J., S. L. Bruening, D. M. Schultz, and J. V. Cortinas, 2003: Improving snowfall forecasting by diagnosing snow density. Wea. Forecasting, 18, 264-287, https://doi.org/10.1175/ 1520-0434(2003)018<0264:ISFBDS > 2.0.CO;2.

Rudlosky, S. D., S. J. Goodman, K. S. Virts, and E. C. Bruning, 2019: Initial Geostationary Lightning Mapper observations. Geophys. Res. Lett., 46, 1097-1104, https://doi.org/10.1029/ 2018GL081052

Rust, W. D., and R. J. Trapp, 2002: Initial balloon soundings of the electric field in winter nimbostratus clouds in the USA. Geophys. Res. Lett., 29, 1959, https://doi.org/10.1029/2002GL015278.

Saunders, C. P. R., H. Bax-Horman, C. Emersic, E. E. Avila, and N. E. Castellano, 2006: Laboratory studies of the effect of cloud conditions on graupel/crystal charge transfer in thun derstorm electrification. Quart. J. Roy. Meteor. Soc., 132, 2653-2673, https://doi.org/10.1256/QJ.05.218.

Schmit, T. J., M. M. Gunshor, W. P. Menzel, J. J. Gurka, J. Li, and A. S Bachmeier, 2005: Introducing the next-generation Advanced Baseline Imager on GOES-R. Bull. Amer. Meteor. Soc., 86, 10791096, https://doi.org/10.1175/BAMS-86-8-1079.

Schrom, R. S., and M. R. Kumjian, 2016: Connecting microphysical processes in Colorado winter storms with vertical profiles of radar variables. J. Appl. Meteor. Climatol., 55, 1771-1787, https://doi.org/10.1175/JAMC-D-15-0338.1.

- and —, 2019: A probabilistic radar forward model for branched planar ice crystals. J. Appl. Meteor. Climatol., 58, 1245-1265, https://doi.org/10.1175/JAMC-D-18-0204.1.

Schultz, C. J., L. D. Carey, E. V. Schultz, and R. J. Blakeslee, 2017 Kinematic and microphysical significance of lightning jumps 
versus nonjump increases in total flash rate. Wea. Forecasting, 32, 275-288, https://doi.org/10.1175/WAF-D-15-0175.1.

, T. J. Lang, E. C. Bruning, K. M. Calhoun, S. Harkema, and N. Curtis, 2018: Characteristics of lightning within electrified snowfall events using lightning mapping arrays. J. Geophys. Res. Atmos., 123, 2347-2367, https://doi.org/ 10.1002/2017JD027821.

Schultz, D. M., 1999: Lake-effect snowstorms in northern Utah and western New York with and without lightning. Wea. Forecasting, 14, 1023-1031, https://doi.org/10.1175/15200434(1999)014<1023:LESINU>2.0.CO;2.

Seroka, G. N., R. E. Orville, and C. Schumacher, 2012: Radar nowcasting of total lightning over the Kennedy Space Center. Wea. Forecasting, 27, 189-204, https://doi.org/10.1175/ WAF-D-11-00035.1.

Skofronick-Jackson, G., and Coauthors, 2017: The Global Precipitation Measurement (GPM) mission for science and society. Bull. Amer. Meteor. Soc., 98, 1679-1695, https://doi.org/10.1175/BAMS-D-1500306.1.

Smith, T. M., and Coauthors, 2016: Multi-Radar Multi-Sensor (MRMS) severe weather and aviation products: Initial operating capabilities. Bull. Amer. Meteor. Soc., 97, 1617-1630, https://doi.org/10.1175/BAMS-D-14-00173.1.

Takahashi, T., 1978: Riming electrification as a charge generation mechanism in thunderstorms. J. Atmos. Sci., 35, 1536-1548, https://doi.org/10.1175/1520-0469(1978)035<1536: REAACG $>2.0 . \mathrm{CO} ; 2$.

_- T. Tajiri, and Y. Sonoi, 1999: Charges on graupel and snow crystals and the electrical structure of winter thunderstorms. J. Atmos. Sci., 56, 1561-1578, https://doi.org/10.1175/15200469(1999)056<1561:COGASC > 2.0.CO;2.

- S. Sugimoto, T. Kawano, and K. Suzuki, 2017: Riming electrification in Hokuriku winter clouds and comparison with laboratory observations. J. Atmos. Sci., 74, 431-447, https:// doi.org/10.1175/JAS-D-16-0154.1.

Thompson, E. J., S. A. Rutledge, B. Dolan, V. Chandrasekar, and B. L. Cheong, 2014: A dual-polarization radar hydrometeor classification algorithm for winter precipitation. J. Atmos. Oceanic Technol., 31, 1457-1481, https://doi.org/ 10.1175/JTECH-D-13-00119.1.

Trapp, R. J., D. M. Schultz, A. V. Ryzhov, and R. L. Holle, 2001: Multiscale structure and evolution of an Oklahoma winter precipitation event. Mon. Wea. Rev., 129, 486-501, https:// doi.org/10.1175/1520-0493(2001)129<0486:MSAEOA>2.0.CO;2.

Uccellini, L. W., P. J. Kocin, R. S. Schneider, P. M. Stokols, and R. A. Dorr, 1995: Forecasting the 12-14 March 1993 superstorm. Bull. Amer. Meteor. Soc., 76, 183-199, https://doi.org/ 10.1175/1520-0477(1995)076<0183:FTMS>2.0.CO;2.

Vincent, B. R., L. D. Carey, D. Schneider, K. Keeter, and R. Gonski, 2003: Using WSR-88D reflectivity data for the prediction of cloud-to-ground lightning: A central North Carolina study. Natl. Wea. Dig., 27, 35-44.

Warner, T. A., T. J. Lang, and W. A. Lyons, 2014: Synoptic scale outbreak of Self-Initiated Upward Lightning (SIUL) from tall structures druing the central U.S. blizzard of 1-2 February 2011. J. Geophys. Res. Atmos., 119, 9530-9548, https://doi.org/ 10.1002/2014JD021691.

Wiesmueller, J., and S. Zubrick, 1998: Evaluation and application of conditional symmetric instability, equivalent potential vorticity, and frontogenetic forcing in an operational forecast environment. Wea. Forecasting, 13, 84-101, https://doi.org/ 10.1175/1520-0434(1998)013<0084:EAAOCS > 2.0.CO;2.

Zhang, J., and Coauthors, 2016: Multi-Radar Multi-Sensor (MRMS) quantitative precipitation estimation: Initial operating capabilities. Bull. Amer. Meteor. Soc., 97, 621-638, https://doi.org/10.1175/BAMS-D-14-00174.1. 